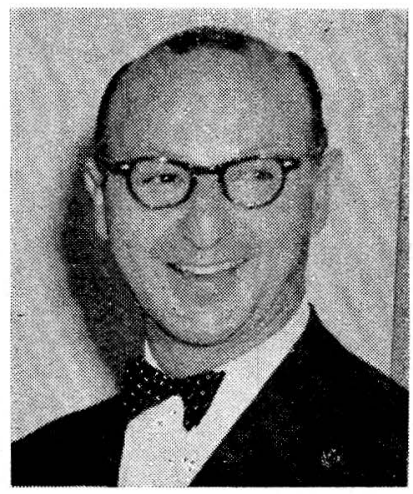

\title{
Dr. RODULFO CAMERO CASTAÑO
}

Con dolorosa sorpresa recibimos la noticia del fallecimiento del eminente Ginecólogo y Obstetra Dr. Rodulfo Camero Castaño, acaecida en la ciudad de Bogotá el día 14 de Mayo.

Todos los órganos publicitarios han hecho el justo elogio de sus condiciones de caballero intachable y de médico de condiciones relievantes.

Egresado de los claustros de la Facultad Nacional de Medicina en el año de 1937, inició su brillante carrera en el Hospital de San José don le desempeñó el cargo de Jefe de Residentes y de Interno de Obstetricia y Ginecología. Posteriormente adelantó estudios de especialización en Buenos Aires, Estocolmo y Nueva York. Con un acerbo de conocimientos y experiencias envidiables, regresó a su pairia $\mathrm{y}$ se constituyó con la fundación de la Clínica Camero en uno de los pioneros de la Obstetricia y Ginecología en nuestro medio.

Vinculado a la Sociedad Colombiana de Obstetricia y Ginecología desde su fundación, fué uno de sus miembros más entusiastas prestándole a través de los años toda su colaboración.

Fué su Vicepresidente en el año de 1954 y Presidente en 1963. Direc tor de la Revista Colombiana de Obstetricia y Ginecología de 1965 a 1967 la llevó a un nivel científico óptimo, apreciable en Colombia $\mathrm{y}$ en el exterior.

Esta Revista, cuyas páginas se honraron tantas veces con sus colaboraciones científicas, rinde un emocionado tributo a su memoria $\mathrm{y}$ presenta el ejemplo nobilísimo de su vida como galardón de nuestra Sociedad. 